Check for updates

Cite this: RSC Adv., 2018, 8, 14040

\title{
A nano-magnetic electrochemical sensor for the determination of mood disorder related substances $\dagger$
}

\author{
Fernando H. Cincotto, (D) *a Daniel A. S. Carvalho, ${ }^{a}$ Thiago C. Canevari, ${ }^{\text {b }}$ \\ Henrique E. Toma, ${ }^{c}$ Orlando Fatibello-Filho (D) ${ }^{a}$ and Fernando C. Moraes ${ }^{\star a}$
}

\begin{abstract}
The simultaneous electrochemical detection of mood disorder related substances, such as amitriptyline, melatonin and tryptophan, was successfully achieved by using a novel nano-magnetic electrochemical sensor design, encompassing $\mathrm{Fe}_{3} \mathrm{O}_{4}$ nanoparticles decorated with carbon quantum dots (MagNPs/ Cdots). The magnetic composite was characterized using HR-TEM microscopy, XRD and Raman spectroscopy, and was applied onto a glassy carbon electrode using a miniature neodymium magnet. The determination of amitriptyline, melatonin and tryptophan was performed by monitoring oxidation promoted by MagNPs/Cdots in BR-buffer at $\mathrm{pH}$ 3.0, which proceeded according to well-defined differential pulse voltammetry peaks, with detection limits of 5.9, 4.4 and $4.2 \mathrm{nmol} \mathrm{L}^{-1}$, respectively. No significant interference was seen from biological interferents such as uric acid, ascorbic acid, dopamine, estriol and $17 \beta$-estradiol. The magnetic hybrid material was highly stable in solution, opening exciting opportunities for the development of low cost and practical electrochemical sensors for the determination of mood disorder related substances in real clinical samples.
\end{abstract}

Received 2nd March 2018

Accepted 3rd April 2018

DOI: $10.1039 / \mathrm{c} 8 \mathrm{ra01857j}$

rsc.li/rsc-advances with depression presents a harmful cycle, in which there is a drastic decrease in the level of tryptophan, minimizing serotonin levels and compromising ML secretion, leading to several mood disorders. In order to treat depression cases or minimize its effects, antidepressants such as amitriptyline (AMP) have been used. AMP belongs to the tricyclic class of drugs, and has a two-mode action in humans. In the pre-synaptic mode, it acts directly on serotonin blocking ${ }^{11}$ and in post-synaptic mode, it regulates levels of beta-adrenergic, histamine and cholinergic blockers. However, AMP, similar to many other tricyclic antidepressants, has several side-effects. ${ }^{12}$ Depending on the dosage of AMP in the blood, it may affect the production of melatonin and tryptophan, worsening some symptoms such as insomnia, seizures, and respiratory problems. ${ }^{\mathbf{1 3 , 1 4}}$ Therefore, in this case, an AMP controlled dosage is required in the human body.

Tadayon et al. ${ }^{15}$ developed an electrochemical sensor based on a nitrogen doped graphene $/ \mathrm{CuCo}_{2} \mathrm{O}_{4}$ nanocomposite for the simultaneous determination of melatonin and tryptophan. The developed sensor was then employed for the simultaneous determination of target analytes with a linear range of 0.010-3.0 $\mu \mathrm{M}$, using differential pulse voltammetry. Detection limits of 0.0049 and $0.0041 \mu \mathrm{M}$ were achieved for melatonin and tryptophan, respectively. In another work, Zeinali et al. ${ }^{\mathbf{1 6}}$ developed a sensor for the simultaneous determination of tryptophan and melatonin. The proposed sensor was an ionic liquid carbon paste electrode modified with reduced graphene oxide decorated with $\mathrm{SnO}_{2}-\mathrm{Co}_{3} \mathrm{O}_{4}$ nanoparticles. A linear response was obtained in the range of 0.02 to $6.00 \mu \mathrm{mol} \mathrm{L}^{-1}$ with detection 
limits of 4.1 and $3.2 \mathrm{nmol} \mathrm{L}^{-1}$ for melatonin and tryptophan, respectively.

Carbon nanoparticles are increasingly being used as electrode modifiers, because they enlarge the active surface area, introducing new functionalities and also improving interfacial electron transfer. ${ }^{17-19}$ A special kind of carbon material that has attracted attention in recent years is carbon quantum dots (Cdots). This nanomaterial consists of very small spherical nanoparticles $(<10 \mathrm{~nm})$, in which carbon atoms are linked by a combination of $\mathrm{sp}^{2}$ and $\mathrm{sp}^{3}$ bonds. Some relevant characteristics of Cdots are their surface stabilization by carboxylic groups, and that they exhibit a high surface area, low toxicity and outstanding optical properties (e.g., stable and strong fluorescence emission).$^{20}$ For this reason, Cdots are suitable for application to surface modification procedures. In addition, their very small diameters may also lead to quantum confinement effects.

On the other hand, magnetic $\mathrm{Fe}_{3} \mathrm{O}_{4}$ nanoparticles (MagNPs) ${ }^{21}$ form another relevant class of nanomaterial, introducing additional advantages such as: non-toxic behavior and facile functionalization; ${ }^{22}$ a large specific surface area which allows binding to large amounts of (bio)molecules; and good magnetic performance when submitted to a miniature, external magnet. Furthermore, a large number of hydroxyl and carboxyl groups can be found on the surface of MagNP prepared in the aqueous phase, favouring the binding of molecules to their surface and facilitating electron transfer at the electrode/ solution interface. ${ }^{23}$

In the present work, a combination of $\mathrm{Fe}_{3} \mathrm{O}_{4}$ magnetic nanoparticles (MagNPs) with carbon nanoparticles (Cdots) was used to generate a versatile electrocatalytic agent, which can be kept on the glassy carbon electrode surface through the application of an external, miniature magnet. This new design of nano-magnetic sensor was employed to quantify amitriptyline in the presence of melatonin and tryptophan, using the nanomagnetic electrochemical sensor, revealing good electroanalytical performance.

\section{Experimental}

\section{Reagents}

All solutions were prepared using purified water from a Barnstead Nanopure system (Thermo Scientific, USA) with a resistivity $\geq 18.2 \mathrm{M} \Omega \mathrm{cm}$. The following analytical grade reagents were purchased from Aldrich and used without further purification: $\mathrm{FeSO}_{4} \cdot 7 \mathrm{H}_{2} \mathrm{O}(\geq 99.0 \%) ; \mathrm{FeCl}_{3}(97 \%)$; $\mathrm{KOH}(\geq 85 \%)$; tetrabutylammonium chloride $(\geq 97.0 \%) ;$ acetone $(\geq 99.9 \%)$; amitriptyline (reference standard); melatonin ( $\geq 98 \%)$; tryptophan (reference standard); $\mathrm{H}_{3} \mathrm{BO}_{3}(\geq 99.5 \%) ;$ and $\mathrm{H}_{3} \mathrm{PO}_{4}$ (analytical grade). $\mathrm{CH}_{3} \mathrm{COOH}$ (reference standard) and $n$-propanol (anhydrous, 99.7\%) were purchased from Synth.

\section{Apparatus and electrochemical measurements}

$\mathrm{X}$-ray powder diffraction (XRD) analysis was performed on a Bruker Phaser diffractometer using a $\mathrm{Cu} \mathrm{K} \alpha$ radiation source $(\lambda=1.54 \AA)$. Raman spectra were recorded using a Horiba/Join
YvonLabran dispersive Raman spectrometer. The spectra were collected over a range from 0 to $2500 \mathrm{~cm}^{-1}$, for $10 \mathrm{~s}$ and 10 cycles of exposure with $520 \mathrm{~nm}$ excitation. High-resolution transmission electron microscopy (HR-TEM) images were obtained with a JEOL transmission electron microscope, operating at 200 $\mathrm{kV}$. Samples of the nanomaterials were dispersed in 1-propanol and then the solutions were dripped onto copper grids covered with ultra-thin carbon film. The electrochemical measurements were performed using an Autolab model PGSTAT 128N potentiostat (Eco Chemie, Utrecht, Netherlands). The electrochemical cell used was based on an arrangement of three electrodes: a working glassy carbon electrode (GCE), encompassing a diskshaped magnet from behind (as displayed in Scheme 1), for concentrating MagNPs or MagNPs/Cdots, separately, on the surface; $\mathrm{Ag} / \mathrm{AgCl}\left(3.0 \mathrm{~mol} \mathrm{~L}^{-1} \mathrm{KCl}\right)$, as a reference electrode; and a platinum wire, as the auxiliary electrode. Cyclic voltammetry (performed over a potential range from 0.0 to $1.15 \mathrm{~V} v s$. $\mathrm{Ag} / \mathrm{AgCl}$, at a scan rate of $20.0 \mathrm{mV} \mathrm{s}^{-1}$ ), differential pulse voltammetry (performed over a potential range from 0.4 to $1.1 \mathrm{~V} v s . \mathrm{Ag} / \mathrm{AgCl}$ in $3.0 \mathrm{~mol} \mathrm{~L}^{-1} \mathrm{KCl}$ ), step potential, pulse amplitude and scan rate measurements were carried out in $5.0 \mathrm{~mL}$ of $0.1 \mathrm{~mol} \mathrm{~L}^{-1}$ Briton-Robinson buffer solution (BR), at pH 3.0.

\section{Synthesis of the MagNPs magnetic nanoparticles}

The iron oxide magnetic nanoparticles (MagNPs) were synthesized using a co-precipitation method. ${ }^{24}$ First, $500 \mathrm{~mL}$ of an aqueous solution was prepared via mixing 0.05 mol L ${ }^{-1} \mathrm{FeCl}_{3}$ with $0.025 \mathrm{~mol} \mathrm{~L}^{-1} \mathrm{FeSO}_{4} \cdot 7 \mathrm{H}_{2} \mathrm{O}$, under stirring and $\mathrm{N}_{2}$ was bubbled for $30 \mathrm{~min}$. Then, $5.0 \mathrm{~g}$ of $\mathrm{KOH}$ was added and the solution was kept under stirring for $1 \mathrm{~h}$. After this, $5.0 \mathrm{~mL}$ of tetrabutylammonium chloride was added and the mixture was kept under stirring for another $10 \mathrm{~min}$. Finally, the MagNPs nanoparticles were separated using an external magnet and washed with two aliquots of acetone and two aliquots of water.

\section{Preparation of the MagNPs/Cdots hybrid material}

Carbon nanoparticles (Cdots) were synthesized via the amperometrically controlled electrolysis of a propanol solution, for $8 \mathrm{~h}$, as previously reported..$^{25}$ This method produces highly stable, electroactive and luminescent carbon nanoparticles, surface functionalized with oxygenated groups, in the form of special carboxylates. The association of Cdots with MagNPs was carried out according to the following procedure. $3.0 \mathrm{~g}$ of MagNPs were dispersed in $10.0 \mathrm{~mL}$ of the $n$-propanol containing Cdots. The mixture was placed in an ultrasonic bath for $30 \mathrm{~min}$ and kept in

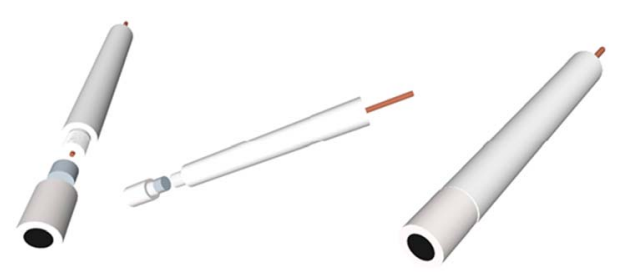

Scheme 1 Architectural illustration of the working electrode, showing a disk-shaped miniature neodymium magnet behind the glassy carbon. 
a closed bottle for $24 \mathrm{~h}$. The anchoring of Cdots on the MagNPs surfaces proceeds spontaneously because of the favourable interactions promoted by the surface functional groups, as well as the electrostatic attraction from the remaining tetrabutylammonium species on the MagNPs surfaces. This new material was denominated MagNPs/Cdots. After association, MagNPs/ Cdots were magnetically confined and washed with water in order to remove any excess free Cdots from the hybrid material.

\section{Electrode preparation}

To prepare the electrode, the GCE was polished to a mirror-like finish using $0.3 \mu \mathrm{m}$ alumina slurry and sonicated in ultrapure water and ethanol. The electrode was first coated with MagNPs/ Cdots by depositing a $10 \mu \mathrm{L}$ aliquot of a $0.5 \mathrm{mg} \mathrm{mL}^{-1}$ aqueous dispersion of the nanocomposite on the electrode surface. The electrode was immersed in water to remove the particles that were not fixed by the magnet contained behind the electrode (see Scheme 1). For comparison, GCE/MagNPs without Cdots were also prepared as described above.

\section{Results and discussion}

\section{Characterization of nanomaterials}

The iron oxide magnetic nanoparticles (MagNPs), Cdots and MagNPs/Cdots composite were characterized using HR-TEM microscopy, XRD patterns and Raman spectroscopy, as shown in Fig. 1.

A HR-TEM micrograph of MagNPs is shown in Fig. 1A, with corresponding crystalline spherical nanoparticles with an average size of $20 \mathrm{~nm}$ indicated by arrows. It is possible to observe the interplanar distance, which is close to $0.30 \mathrm{~nm}$, corresponding to the (220) plane of the spinel structure presented by MagNPs. ${ }^{21}$ The inset of Fig. 1A shows the XRD pattern of the iron oxide $\left(\mathrm{Fe}_{3} \mathrm{O}_{4}\right)$ magnetic nanoparticles (MagNPs). The fingerprint peaks of $\mathrm{Fe}_{3} \mathrm{O}_{4}$ were observed in the following $2 \theta$ sequence: $(220)$ at $30.1^{\circ} ;(311)$ at $35.5^{\circ} ;(400)$ at $43.2^{\circ} ;(422)$ at $53.5^{\circ}$; (511) at $57.2^{\circ}$; and $(440)$ at $62.8^{\circ}$. These results are consistent with those reported in the literature ${ }^{26,27}$ for $\mathrm{Fe}_{3} \mathrm{O}_{4}$.

Fig. 1B shows an HR-TEM microscopy image of Cdots, as prepared, exhibiting an average size smaller than $5.0 \mathrm{~nm}$ and a crystalline structure with an interplanar distance close to $0.2 \mathrm{~nm}$, corresponding to the (102) diffraction plane, which is attributed to the graphitic phase.$^{20} \mathrm{~A}$ typical Raman spectrum of Cdots is exhibited in the inset of Fig. $1 \mathrm{~B}$. The $\mathrm{D}$ and $\mathrm{G}$ bands at 1360 and $1593 \mathrm{~cm}^{-1}$, respectively, can be seen, with an $I_{\mathrm{D}} / I_{\mathrm{G}}$ ratio estimated at 0.89 . The $D_{\text {Band }}$ magnitude could be related to the presence of defects attributed to the oxygenated functional groups on the material surface and the small size of the particles. ${ }^{28,29}$ Comparing with other reports in the literature, ${ }^{30,31}$ the $I_{\mathrm{D}} / I_{\mathrm{G}}$ ratio, and the shapes and positions of the appearing bands
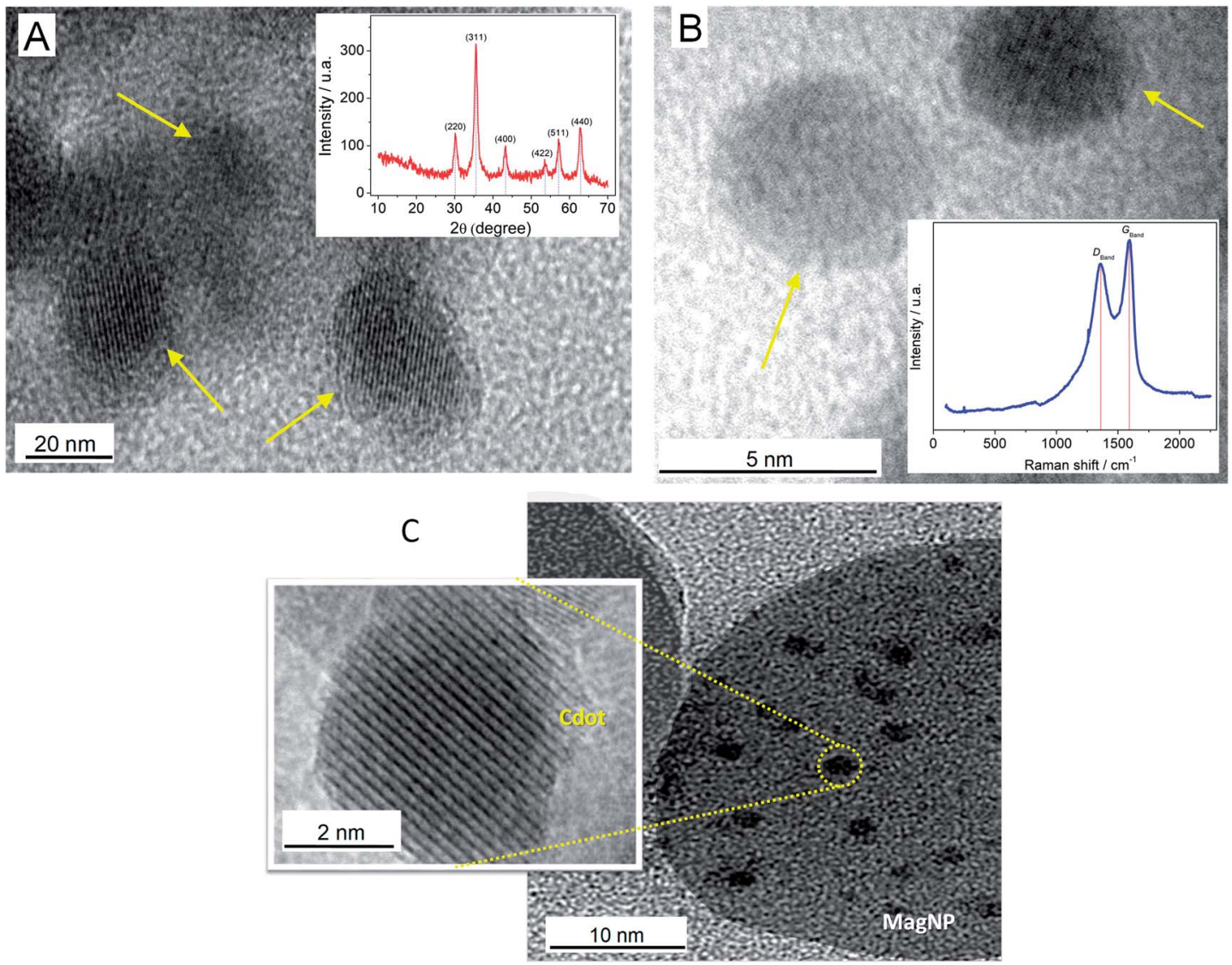

Fig. 1 (A) A HR-TEM micrograph of MagNPs. Inset: an XRD pattern of MagNPs. (B) A HR-TEM micrograph of Cdots. Inset: a Raman spectrum of Cdots. (C) A HR-TEM micrograph of magnetic nanoparticles incorporating Cdots (MagNPs/Cdots). Inset: an amplification of a Cdots particle. 
in the spectrum are coherent with the nature of Cdots. A HRTEM microscopy image of the MagNPs/Cdot material is shown in Fig. 1C. The $\mathrm{Fe}_{3} \mathrm{O}_{4}$ magnetic nanoparticles have a size close to $30.0 \mathrm{~nm}$, and it is possible to visualize that Cdots are supported on MagNPs.

The electrochemical behavior of a $10.0 \mu \mathrm{mol} \mathrm{L}{ }^{-1}$ mixture containing amitriptyline (AMP), melatonin (ML) and tryptophan (TP) was evaluated using a bare GC electrode, GC/MagNPs and GC/MagNPs/Cdots. The cyclic voltammograms shown in Fig. 2 were obtained in $0.1 \mathrm{~mol} \mathrm{~L}^{-1}$ Britton-Robinson buffer solution (BR-buffer), at $\mathrm{pH}$ 3.0, over a potential range from 0.0 to $+1.15 \mathrm{~V}$, with a scan rate of $20 \mathrm{mV} \mathrm{s}^{-1}$.

In Fig. 2 (curve a), no electrochemical processes were observed in the voltammetric response of GC/MagNPs/Cdots in the absence of the AMP, ML and TP standard solution. However, in curve (d), which results from GC/MagNPs/Cdots, the electrochemical response in the presence of a solution containing $10.0 \mu \mathrm{mol} \mathrm{L}^{-1}$ AMP, ML and TP reveals three well-defined irreversible oxidation peaks at $+0.63 \mathrm{~V},+0.85 \mathrm{~V},+1.01 \mathrm{~V}$, corresponding to the oxidation of AMP, ML and TP, respectively. It has been reported $^{32-34}$ that these electrochemical processes correspond to the oxidation processes represented in Scheme 2.

Differential pulse voltammetry (DPV) experiments were carried out in order to obtain a better observation of the voltammetric processes involved in the simultaneous quantification of AMP, ML and TP. They used the DPV parameters of a potential range from 0.0 to $+1.2 \mathrm{~V}$, a potential scan rate of $5 \mathrm{mV} \mathrm{s}^{-1}$, a step potential of $2 \mathrm{mV}$, and a pulse amplitude of $50 \mathrm{mV}$. The measurements were performed in $0.1 \mathrm{~mol} \mathrm{~L}^{-1} \mathrm{BR}-$ buffer at pH 3.0 containing a $10.0 \mu \mathrm{mol} \mathrm{L}^{-1}$ mixed solution of amitriptyline, melatonin and tryptophan.

It can be observed in Fig. 3 that the voltammetric profiles exhibit peaks at almost constant potentials around $+0.57 \mathrm{~V}$, $0.79 \mathrm{~V}$, and $0.97 \mathrm{~V} v s$. $\mathrm{Ag} / \mathrm{AgCl}$, corresponding to AMP, ML and TP species, respectively, for all electrodes studied. However, the GC/MagNPs/Cdots composite electrode (curve d) displayed a higher anodic current magnitude for the mixed solution in comparison to the current observed from the other electrodes.

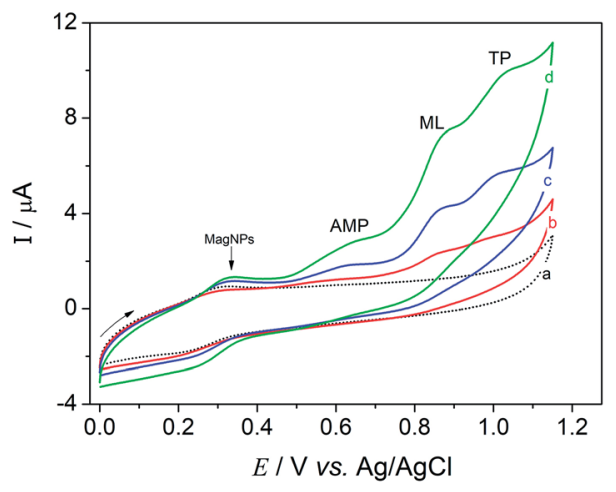

Fig. 2 Cyclic voltammograms obtained in $0.1 \mathrm{~mol} \mathrm{~L}^{-1} \mathrm{BR}$-buffer at $\mathrm{pH}$ 3.0, at a scan rate of $20.0 \mathrm{mV} \mathrm{s}^{-1}$, containing a $10.0 \mu \mathrm{mol} \mathrm{L}{ }^{-1}$ mixed solution of amitriptyline (AMP), melatonin (ML) and tryptophan (TP) using the following set-ups: (a) GC/MagNPs/Cdots in the absence of the AMP, ML and TP standard solution, (b) bare GC, (c) GC/MagNPs and (d) a GCE/MagNPs/Cdots composite.
GC/MagNPs/Cdots yielded excellent peak separation, accompanied by an almost 2.5 -fold increase in the oxidation peak currents from the analytes, as compared to the electrode prepared in the absence of Cdots (curve c). The current increase seems to reflect the increase in the electroactive surface area from the MagNPs/Cdots composite. Such properties make the GCE/MagNPs/Cdots composite electrode a promising choice for the simultaneous determination of amitriptyline, melatonin and tryptophan in real samples.

The analytical technique used for the simultaneous quantification of AMP, ML and TP was DPV. Thus, in order to observe the improvement from electrode modification, the influence of the differential pulse voltammetry (DPV) parameters was then investigated. First, the effect of potential scan rate was studied over a range from 2.0 to $15 \mathrm{mV} \mathrm{s}^{-1}$, with the step potential kept constant at $2 \mathrm{mV}$ with an amplitude of $50 \mathrm{mV}$. A scan rate of $5 \mathrm{mV} \mathrm{s}^{-1}$ was chosen because it exhibited a higher anodic peak current (ESI Fig. 1S $\dagger$ ). Higher scan rates caused a loss of peak definition and a lower anodic peak current from mixture oxidation. The next step was to keep the step potential constant at $2 \mathrm{mV}$ and the scan rate at $5 \mathrm{mV} \mathrm{s}^{-1}$ while the amplitude was varied from 10 to $100 \mathrm{mV}$ (ESI Fig. 2S†). No significant increase in peak width was observed for mixture oxidation, even at amplitudes greater than $50 \mathrm{mV}$. Since the peak currents were proportional to the increase in amplitude, $50 \mathrm{mV}$ was chosen as the optimized DPV amplitude. The final experiment involved holding the amplitude constant at $50 \mathrm{mV}$ and the potential scan rate at $5 \mathrm{mV} \mathrm{s}^{-1}$, and studying the effects of step potential changes over a range from 1 to $10 \mathrm{mV}$ (ESI Fig. $3 \mathrm{~S} \dagger$ ). For step potentials greater than $2 \mathrm{mV}$, deformation of the voltammetric profiles was observed and the anodic peak current for a mixed solution decreased in height, so a step potential increment of $2 \mathrm{mV}$ was chosen.

\section{Selectivity studies}

The ability to determine a mixed solution of amitriptyline, melatonin and tryptophan in the presence of other compounds was investigated. The selectivity of the GC/MagNPs/Cdots composite was evaluated by measuring the DPV responses generated by 4 different potential interfering substances at a 20 $\mu \mathrm{mol} \mathrm{L} \mathrm{L}^{-1}$ concentration, and comparing these with that obtained for a $10 \mu \mathrm{mol} \mathrm{L}{ }^{-1}$ concentration of the mixture, under similar measuring conditions. Very low analytical signals were recorded for ascorbic acid $(0.6 \%)$, uric acid $(0.8 \%)$, dopamine $(1.4 \%)$, estriol $(0.2 \%)$ and $17 \beta$-estradiol $(0.3 \%)$, suggesting the high selectivity of the GC/MagNPs/Cdots composite electrode (ESI Table $1 \mathrm{~S} \dagger$ ).

\section{Analytical characteristics}

DPV experiments were carried out in triplicate using the optimized experimental parameters to obtain an analytical curve for the simultaneous determination of amitriptyline, melatonin and tryptophan with the GC/MagNPs/Cdots composite electrode in $0.1 \mathrm{~mol} \mathrm{~L}^{-1}$ BR-buffer at $\mathrm{pH}$ 3.0. To evaluate the performance of the composite, determinations of individual analytes were performed in the presence of the other two 


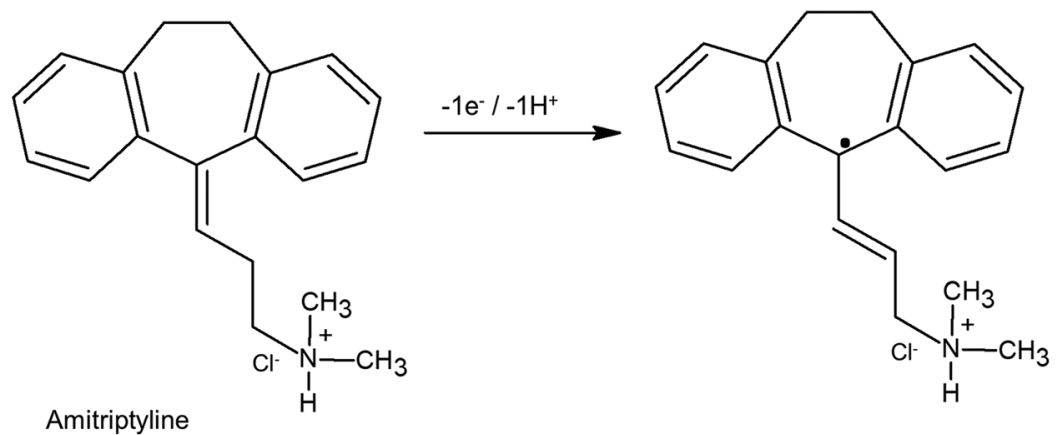<smiles>CO[C+]1C=CC2=NC=C(CCNC(C)=O)C2=C[C+]1C</smiles>

Melatonin<smiles>N[C@@H](Cc1c[nH]c2ccccc12)C(=O)O</smiles><smiles>N[C@@H](CO)CC1=CN=C2C=CC(=O)C=C12</smiles>

Tryptophan

Scheme 2 The electrochemical oxidation processes of amitriptyline, melatonin and tryptophan.

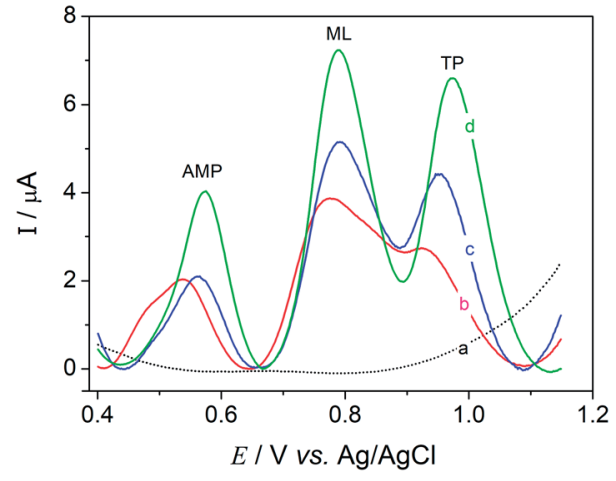

Fig. 3 DPV voltammograms obtained under optimized conditions in $0.1 \mathrm{~mol} \mathrm{~L}^{-1}$ BR-buffer at $\mathrm{pH}$ 3.0, containing a $10.0 \mu \mathrm{mol} \mathrm{L}{ }^{-1}$ mixed solution of AMP, ML and TP using the following electrodes: (a) a GC/ MagNPs/Cdots blank solution; (b) bare GC; (c) GC/MagNPs and (d) a GC/MagNPs/Cdots composite.

studied substances. The analytical curve obtained for amitriptyline exhibited a linear range from 0.05 to $7.5 \mu \mathrm{mol} \mathrm{L}{ }^{-1}\left(R^{2}=\right.$ 0.9975 ) in the presence of melatonin and tryptophan, each at $4.0 \mu \mathrm{mol} \mathrm{L}{ }^{-1}$, as shown in ESI Fig. $4 \mathrm{~S}(\mathrm{~A}$ and $\mathrm{B}) . \dagger$ The limit of detection (LOD) for amitriptyline was calculated as $8.1 \mathrm{nmol}$ $\mathrm{L}^{-1}$, and a sensitivity of $0.37 \mu \mathrm{A} \mu \mathrm{mol}^{-1} \mathrm{~L}^{-1}$ was obtained. Similarly, an analytical curve for melatonin over a range from 0.05 to $12.50 \mu \mathrm{mol} \mathrm{L}^{-1}\left(R^{2}=0.9988\right)$ was performed in the presence of amitriptyline and tryptophan, each at $4.0 \mu \mathrm{mol} \mathrm{L}^{-1}$ (ESI Fig. 5S(A and B) $\dagger$ ). The LOD for melatonin was calculated as $7.8 \mathrm{nmol} \mathrm{L}{ }^{-1}$ and a sensitivity of $0.38 \mu \mathrm{A} \mu \mathrm{mol}^{-1} \mathrm{~L}^{-1}$ was obtained. Also for collecting individual analytical curves in the presence of the other two analytes, an analytical curve for tryptophan over a range from 0.05 to $19.50 \mu \mathrm{mol} \mathrm{L}^{-1}\left(R^{2}=\right.$ 0.9989) was obtained in the presence of amitriptyline and melatonin, each at $4.0 \mu \mathrm{mol} \mathrm{L}^{-1}$ (ESI Fig. $6 \mathrm{~S}(\mathrm{~A}$ and $\mathrm{B}$ ) $\dagger$ ). The LOD for tryptophan was calculated as $6.0 \mathrm{nmol} \mathrm{L}^{-1}$ and a sensitivity of $0.49 \mu \mathrm{A} \mu \mathrm{mol}^{-1} \mathrm{~L}^{-1}$ was obtained.

Fig. 4 shows the DPV response for the simultaneous determination of amitriptyline melatonin and tryptophan using the GC/MagNPs/Cdots composite electrode in $0.1 \mathrm{~mol} \mathrm{~L}^{-1} \mathrm{BR}$ buffer at $\mathrm{pH}$ 3.0. The study was conducted between -0.35 and $1.25 \mathrm{~V}$, and the electrochemical oxidation of the analytes was performed at variable concentrations, each over the range from 0.05 to $13.5 \mu \mathrm{mol} \mathrm{L}^{-1}$.

As in the individual determinations of the analytes, it was possible to observe an increase in the analytical signal upon an 

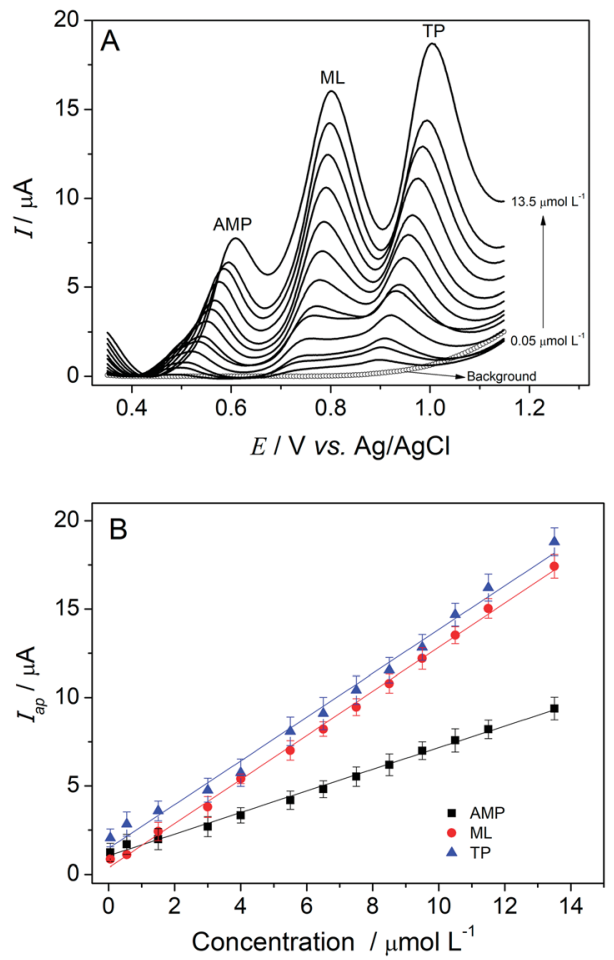

Fig. 4 (A) Differential pulse voltammetry data for the simultaneous determination of amitriptyline, melatonin and tryptophan using the GC/MagNPs/Cdots composite electrode, in $0.1 \mathrm{~mol} \mathrm{~L}^{-1} \mathrm{BR}$-buffer at $\mathrm{pH}$ 3.0. (B) Analytical curves constructed for the simultaneous determination of AMP, ML and TP using the nano-magnetic electrochemical sensor

increase in the concentration of each analyte (amitriptyline, melatonin and tryptophan). Fig. 4B shows analytical curves for each analyte, determined simultaneously in the same sample matrix.

The following equations have been obtained for the determination of each analyte (amitriptyline, melatonin and tryptophan) in the sample matrix:
(AMP) $I_{\text {ap }}(\mu \mathrm{A})=1.04(\mu \mathrm{A})+0.61\left(\mu \mathrm{A} \mu \mathrm{mol}^{-1} \mathrm{~L}^{-1}\right)$ [amitriptyline] ( $\mu \mathrm{mol} \mathrm{L}^{-1}$ ), with $R^{2}=0.996$ and $n=13$

(ML) $I_{\text {ap }}(\mu \mathrm{A})=0.37(\mu \mathrm{A})+1.24\left(\mu \mathrm{A} \mu \mathrm{mol}^{-1} \mathrm{~L}^{-1}\right)$ [melatonin] $\left(\mu \mathrm{mol} \mathrm{L}{ }^{-1}\right)$, with $R^{2}=0.998$ and $n=13$

(TP) $I_{\text {ap }}(\mu \mathrm{A})=1.46(\mu \mathrm{A})+1.23\left(\mu \mathrm{A} \mu \mathrm{mol}^{-1} \mathrm{~L}^{-1}\right)$ [tryptophan] $\left(\mu \mathrm{mol} \mathrm{L}^{-1}\right)$, with $R^{2}=0.995$ and $n=13$

The detection limits for the simultaneous determination of AMP, ML and TP were calculated as recommended by IUPAC, ${ }^{35}$ using the $3 \sigma /$ slope ratio, (where $\sigma$ is the standard deviation of the mean current over 10 differential pulse voltammograms of a blank), and they were respectively equal to $5.9 \mathrm{nmol} \mathrm{L}^{-1}$ for amitriptyline, $4.4 \mathrm{nmol} \mathrm{L}^{-1}$ for melatonin and $4.2 \mathrm{nmol} \mathrm{L}^{-1}$ for tryptophan.

Table 1 summarizes a comparison of the analytical characteristics of different electrochemical sensors described previously for amitriptyline, melatonin and tryptophan determination, and the results obtained in this work.

According to Table 1, the GC/MagNPs/Cdots composite electrode for amitriptyline, melatonin and tryptophan detection shows a good limit of detection and a wide linear range from using the new and easy-to-prepare nanomaterial. This work represents the first proposal for an electrochemical sensor for the simultaneous detection of amitriptyline, melatonin and tryptophan, suggesting the potential to improve the selectivity of this sensor in comparison to others based on non-selective nanomaterials.

The inter-assay precision (reproducibility) of the $\mathrm{GC} /$ MagNPs/Cdots composite electrode was measured from eleven experiments, in which each experiment consisted of seven sequential DPV voltammograms. These measurements were performed on different days. The DPV voltammograms were performed in $0.1 \mathrm{~mol} \mathrm{~L}^{-1} \mathrm{BR}$-buffer, at $\mathrm{pH} 3.0$, containing a 10.0 $\mu \mathrm{mol} \mathrm{L}{ }^{-1}$ mixed solution of amitriptyline, melatonin and tryptophan. The RSD was calculated as $2.1 \%$. In addition, intraassay precision tests (repeatability) were performed from

Table 1 A comparison of different electrochemical sensors for amitriptyline, melatonin and tryptophan ${ }^{a}$

\begin{tabular}{|c|c|c|c|c|c|c|c|}
\hline Material & \multicolumn{2}{|l|}{ Amitriptyline } & \multicolumn{2}{|l|}{ Melatonin } & \multicolumn{2}{|l|}{ Tryptophan } & Reference \\
\hline AuNPs@bPEI-CHS & $0.1-700.0$ & 0.034 & - & - & - & - & 36 \\
\hline AMT-MT & $100.0-10000.0$ & 67.3 & - & - & - & - & 37 \\
\hline $\mathrm{GRT} / \mathrm{SiO}_{2} / \mathrm{Al}_{2} \mathrm{O}_{3} / \mathrm{Nb}_{2} \mathrm{O}_{5} / \mathrm{DNA}$ & $10.0-80.0$ & 0.13 & - & - & - & - & 38 \\
\hline $\mathrm{ZnFe}_{2} \mathrm{O}_{4} \mathrm{NPs} / \mathrm{CPE}$ & - & - & - & - & $0.1-200.0$ & 0.040 & 39 \\
\hline GCE/MagNPs/Cdots & $0.05-13.50$ & 0.0059 & $0.05-13.50$ & 0.0044 & $0.05-13.50$ & 0.0042 & This work \\
\hline
\end{tabular}

${ }^{a}$ LOD: limit of detection; AuNPs@bPEI-CHS : Nafion-gold nanoparticles@branched polyethyleneimine-derived carbon hollow spheres; AMT-MT: amitriptyline-molybdotungstate; $\mathrm{GRT} / \mathrm{SiO}_{2} / \mathrm{Al}_{2} \mathrm{O}_{3} / \mathrm{Nb}_{2} \mathrm{O}_{5} / \mathrm{DNA}$ : graphite and silica modified with niobium oxide, alumina and $\mathrm{DNA}$; $\mathrm{SnO}{ }_{2}^{-}$ $\mathrm{Co}_{3} \mathrm{O}_{4} @ \mathrm{rGO} / \mathrm{IL} / \mathrm{CPE}$ : ionic liquid carbon paste electrode modified with $\mathrm{SnO}_{2}-\mathrm{Co}_{3} \mathrm{O}_{4}$ and reduced graphene oxide; $\mathrm{CuCo} \mathrm{O}_{4} / \mathrm{N}-\mathrm{RGO} / \mathrm{CPE}$ : nitrogen-doped graphene nanosheets/ $\mathrm{CuCO}_{2} \mathrm{O}_{4}$ nanoparticles/carbon paste electrode; and $\mathrm{ZnFe}_{2} \mathrm{O}_{4}$ NPs/CPE: carbon paste electrode modified with zinc ferrite nanoparticles. 
eleven DPV voltammograms of that same solution. The RSD was found to be $0.85 \%$. Another important result is that the sensor remained stable, exhibiting the same electrochemical response for more than 3 weeks (from about thirty determinations using immobilized material on the electrode surface). The electrode was stored in a desiccator when not in use.

\section{Conclusions}

The hybrid particles synthesized (MagNPs/Cdots) were composed of magnetic $\mathrm{Fe}_{3} \mathrm{O}_{4}$ (particles with an average diameter size of $20 \mathrm{~nm}$ ) decorated with carbon dots (Cdots) (crystalline structure and a diameter of around $5.0 \mathrm{~nm}$ ), as shown using HR-TEM microscopy, XRD patterns and Raman spectroscopy. The magnetic hybrid material presented a good electrochemical response during the simultaneous electrochemical detection of the amitriptyline (AMP) antidepressant drug, in the presence of the melatonin (ML) hormone and tryptophan (TP) amino acid. The MagNP/Cdot hybrid material showed high sensitivity and excellent selectivity for such species, with a low detection limit of $5.9 \mathrm{nmol} \mathrm{L}{ }^{-1}$ for amitriptyline, $4.4 \mathrm{nmol} \mathrm{L}^{-1}$ for melatonin, and $4.2 \mathrm{nmol} \mathrm{L}^{-1}$ for tryptophan. No significant interference was observed from potential biological interferents such as uric acid, ascorbic acid, dopamine, estriol and $17 \beta$ estradiol. In addition, the magnetic hybrid material was highly stable in solution, and can suggest exciting perspectives for developing electrochemical sensors for the determination of AMP, ML and TP in real clinical samples.

\section{Conflicts of interest}

There are no conflicts to declare.

\section{Acknowledgements}

The authors gratefully acknowledge the Brazilian agencies FAPESP for funding resources to Cincotto, F. H. (2016/16565-5), Moraes, F. C. (2016/12926-3), Canevari, T. C. (2016/12519-9), Toma, H. E. (2013/24725-4), Fatibello-Filho (2011/13312-5), CAPES and CNPq (444150/2014-5, 400412/2016-0) and Mackpesquisa for financial support.

\section{References}

1 United Nations News Centre, http:/www.un.org/apps/news/ story.asp?NewsId=56230\#.WdI3mGhSwdW, 2017.

2 S. J. Mathew and M. Lijffijt, Am. J. Psychiatry, 2017, 174, 3-5. 3 A. Pan, N. Keum, O. I. Okereke, Q. Sun, M. Kivimaki, R. R. Rubin and F. B. Hu, Diabetes Care, 2012, 35, 1171-1180.

4 A. Pan and F. B. Hu, Response to Comment on: Pan et al. Bidirectional association between depression and metabolic syndrome: A systematic review and metaanalysis of epidemiological studies, Diabetes Care, 2012, 35, 1171-1180; Diabetes Care, 2013, 36.

5 P. Brunault, A. L. Champagne, G. Huguet, I. Suzanne, J. L. Senon, G. Body, E. Rusch, G. Magnin, M. Voyer, C. Réveillère and V. Camus, Psycho-Oncol., 2016, 25, 513-520.
6 P. J. Cowen, M. Parry-Billings and E. A. Newsholme, J. Affective Disord., 1989, 16, 27-31.

7 Z. Akpinar, S. Tokgöz, H. Gökbel, N. Okudan, F. Uğuz and G. Yilmaz, Psychiatry Res., 2008, 161, 253-257.

8 E. A. Ogłodek, M. J. Just, A. R. Szromek and A. Araszkiewicz, Psychiatry Res., 2016, 68, 945-951.

9 L. Melamud, D. Golan, R. Luboshitzky, I. Lavi and A. Miller, J. Neurol. Sci., 2012, 314, 37-40.

10 S. N. Young and M. Leyton, Pharmacol., Biochem. Behav., 2002, 71, 857-865.

11 K. H. Lu and J. Meites, Endocrinology, 1973, 93, 152-155.

12 D. S. Charney, G. R. Heninger and D. E. Sternberg, Arch. Gen. Psychiatry, 1984, 41, 359-365.

13 C. B. Brink, J. D. Clapton, B. E. Eagar and B. H. Harvey, J. Neural Transm., 2008, 115, 117-125.

14 R. I. Shader and D. J. Greenblatt, J. Clin. Psychopharmacol., 1987, 7, 65.

15 F. Tadayon and Z. Sepehri, RSC Adv., 2015, 5, 65560-65568. $16 \mathrm{H}$. Zeinali, H. Bagheri, Z. Monsef-Khoshhesab, H. Khoshsafar and A. Hajian, Mater. Sci. Eng., C, 2017, 71, 386-394.

17 F. H. Cincotto, D. L. C. Golinelli, S. A. S. Machado and F. C. Moraes, Sens. Actuators, B, 2017, 239, 488-493.

18 T. M. Prado, F. H. Cincotto, F. C. Moraes and S. A. S. Machado, Electroanalysis, 2017, 29, 1278-1285.

19 E. Povedano, F. H. Cincotto, C. Parrado, P. Díez, A. Sánchez, T. C. Canevari, S. A. S. Machado, J. M. Pingarrón and R. Villalonga, Biosens. Bioelectron., 2017, 89, 343-351.

20 T. C. Canevari, F. H. Cincotto, M. Nakamura, S. A. S. Machado and H. E. Toma, Anal. Methods, 2016, 8, 7254-7259.

21 T. C. Canevari, F. H. Cincotto, D. Gomes, R. Landers and H. E. Toma, Electroanalysis, 2017, 29, 1968-1975.

22 V. Serafín, R. M. Torrente-Rodríguez, M. Batlle, P. García de Frutos, S. Campuzano, P. Yáñez-Sedeño and J. M. Pingarrón, Microchim. Acta, 2017, 1-8, DOI: 10.1007/s00604-017-2455-1.

23 P. Yáñez-Sedeño, S. Campuzano and J. M. Pingarrón, Anal. Chim. Acta, 2017, 960, 1-17.

24 M. Yamaura, R. L. Camilo, L. C. Sampaio, M. A. Macêdo, M. Nakamura and H. E. Toma, J. Magn. Magn. Mater., 2004, 279, 210-217.

25 T. C. Canevari, M. Nakamura, F. H. Cincotto, F. M. De Melo and H. E. Toma, Electrochim. Acta, 2016, 209, 464-470.

26 N. C. C. Lobato, M. B. Mansur and A. De Mello Ferreira, Mater. Res., 2017, 20, 736-746.

27 A. K. Swain, L. Pradhan and D. Bahadur, ACS Appl. Mater. Interfaces, 2015, 7, 8013-8022.

28 H. Li, Z. Kang, Y. Liu and S. T. Lee, J. Mater. Chem., 2012, 22, 24230-24253.

29 F. C. Moraes, R. G. Freitas, R. Pereira, L. F. Gorup, A. Cuesta and E. C. Pereira, Carbon, 2015, 91, 11-19.

30 H. Ding, L. W. Cheng, Y. Y. Ma, J. L. Kong and H. M. Xiong, New J. Chem., 2013, 37, 2515-2520.

31 P. Atienzar, A. Primo, C. Lavorato, R. Molinari and H. García, Langmuir, 2013, 29, 6141-6146. 
32 R. A. De Toledo, L. H. Mazo, M. C. Dos Santos, K. M. Honório, A. B. F. Da Silva and É. T. G. Cavalheiro, Quim. Nova, 2005, 28, 456-461.

33 A. Levent, Diamond Relat. Mater., 2012, 21, 114-119.

34 S. Shahrokhian and L. Fotouhi, Sens. Actuators, B, 2007, 123, 942-949.

35 A. M. Committee, Analyst, 1987, 112, 119.
36 Z. R. Zad, S. S. H. Davarani, A. R. Taheri and Y. Bide, Biosens. Bioelectron., 2016, 86, 616-622.

37 N. Rahman and S. Khan, J. Electroanal. Chem., 2016, 777, 92100.

38 J. P. Marco, K. B. Borges, C. R. T. Tarley, E. S. Ribeiro and A. C. Pereira, J. Electroanal. Chem., 2013, 704, 159-168.

39 S. M. Ghoreishi and M. Malekian, J. Electroanal. Chem., 2017, 805, 1-10. 